\title{
Neonatal Research Network Terminology
}

National Cancer Institute

\section{Source}

National Cancer Institute. Neonatal Research Network Terminology. NCI Thesaurus.

Code C99147.

Terminology developed by a collaborative effort of the National Cancer Institute's

Enterprise Vocabulary Services, the National Institute of Child Health and Human

Development, and an international group of clinicians and informaticists to support the efforts of the Neonatal Research Network. 